\title{
Analysis of Antigen-Antibody Reactions by High-Performance Liquid Chromatography
}

\author{
Kenji Nakamura, Shinji Satomura, Takumi Tanaka and Shuji MatsuUra \\ Osaka Research Laboratory, Wako Pure Chemical Industries, Ltd., 6-1, Takada, Amagasaki 661, Japan
}

\begin{abstract}
A simple and convenient method for the analysis of antigen-antibody reactions using high-performance liquid chromatography is described. A mixture of human serum albumin and anti-albumin monoclonal antibody in a buffer was analyzed on a gel filtration column. After the free albumin and antibody were rapidly separated from the antibodyantigen immune complex, the three amounts in the mixture were directly calculated from the peak heights. The concentration of the antigen and antibody as well as other reaction conditions were easily varied by this method. The effects of the reaction time, the concentrations of albumin or antibodies, and the $\mathrm{pH}$ were examined. The reactivities of the antigen binding sites of immunoglobulin $G$, pepsin digested fragment $F\left(a b^{\prime}\right)_{2}$ and reduced monomeric form Fab' were studied; the results suggest that the $\mathrm{Fc}$ region of $\mathrm{IgG}$ may participate in the antigen-antibody interaction at those binding sites. Epitope typing of monoclonal antibodies was also carried out with a combination of two antibodies. This represents a new immunochemical technique for characterizing antibodies and for the quantitative assay of protein antigens.
\end{abstract}

Keywords Antibody reaction, albumin, high-performance liquid chromatography, epitope typing, immunoassay

Radio immunoassays ${ }^{1}$, enzyme immunoassays ${ }^{2}$, and time-resolved fluoroimmunoassay ${ }^{3}$ are widely used for the assay of antigens. It has been difficult to monitor antigen-antibody immunoreactions in homogeneous solutions using these methods. Recent techniques for high-performance liquid chromatography (HPLC) provide for a simple and rapid separation of many components in solution. Only a few studies have separated a bound form and a free form in immunoreaction using HPLC; no quantitative analysis has been examined. 4,5

This report describes a new method for the assay of immune complexes in a homogeneous solution by HPLC. After an antigen solution was mixed with an antibody solution, a portion of the mixture was directly analyzed. The amounts of the antibody-antigen immune complex and of the free forms of antigen and antibody were found by this method; characterization of the monoclonal antibodies was easy.

\section{Experimental}
Materials
Monoclonal antibodies (IgG; clone Nos. HA2, HA3, and HA4) against human serum albumin (HSA) were produced by the technique of Köhler and Milstein. ${ }^{6}$ The pepsin-digested fragment of $\operatorname{IgG}\left(F\left(a^{\prime}\right)_{2}\right)$ and the reduced monomeric form of $\mathrm{F}(\mathrm{ab})_{2}$ ( $\left(\mathrm{Fab}^{\prime}\right)$, both obtained from clone No. HA3, were prepared and purified as described by Parham. ${ }^{7}$ The HSA was purchased from

Sigma Chemical Co. (St. Louis, MO), and further purified by gel filtration on Toyopearl HW-55S (Tosoh Co., Japan). All antibodies, their fragments, and HSA were homogeneous by sodium dodecyl sulfatepolyacrylamide gel electrophoresis $(7.5 \%$ polyacrylamide) as well as by HPLC with a gel filtration column (Diol-200, 300 $\times 8 \mathrm{~mm}$ i.d., YMC Co., Japan). The protein concentration was measured using the method of Lowry et al. with human IgG or HSA as the standard. ${ }^{8}$ Molar concentrations of HSA and the antibodies were calculated with the use of the following molecular weights: HSA, 67000; IgG, 156000; F( $\left(\mathrm{ab}^{\prime}\right)_{2}, 92000$; and Fab', 46000. The other reagents were from Wako Pure Chemical Industries Ltd.(Osaka, Japan).

\section{Apparatus}

The HPLC apparatus comprised an LC-6A pump, an SLC-6A autoinjector, an SPD-6AV variable-wavelength detector, and a C-R4A integrator (Shimadzu Co., Kyoto, Japan). The Diol-200 column was eluted with a $50 \mathrm{mM}$ sodium phosphate buffer (pH 7.0) containing $150 \mathrm{mM}$ sodium chloride (buffer A) at a flow rate of $1.0 \mathrm{ml} / \mathrm{min}$. The effluent was monitored by its absorbance at 280 or $220 \mathrm{~nm}$. In the general procedure, unless otherwise specified, $20 \mu \mathrm{l}$ of the antibody solution and $80 \mu \mathrm{l}$ of the HSA solution in buffer A were mixed and allowed to react at room temperature for $20 \mathrm{~min}$. Then, $70 \mu \mathrm{l}$ of the reaction mixture was analyzed by HPLC. The amount of the immune complex was calculated from its peak height on the chromatogram. 


\section{Dissociation of the immune complex}

The immune complex peak was purified by HPLC to give a single peak. It was then treated with guanidine hydrochloride to bring about a dissociation of the antibody and antigen. The purified immune complex $(50 \mu l)$ was mixed with $150 \mu \mathrm{l}$ of a $50 \mathrm{mM}$ Tris-HCl buffer (pH 8.0) containing $150 \mathrm{mM}$ sodium chloride and $8 \mathrm{M}$ guanidine hydrochloride; the resulting mixture was incubated at $37^{\circ} \mathrm{C}$ for $30 \mathrm{~min}$. Then, $100 \mu \mathrm{l}$ of the reaction mixture was put on a Diol-200 column and eluted with the same buffer containing $8 \mathrm{M}$ guanidine hydrochloride at the flow rate of $1 \mathrm{ml} / \mathrm{min}$.

\section{Results and Discussion}

\section{Analysis of immunoreaction products by HPLC}

Figure 1 shows typical HPLC chromatograms of the immunoreaction products. A new peak with a larger molecular mass than the antibody or antigen, themselves, appeared in each reaction mixture. The molecular mass of the new peaks derived from IgG, $F\left(a b^{\prime}\right)_{2}$, and $F a b$ ' were $280000(\mathrm{~A}-2), 210000(\mathrm{~B}-2)$, and $110000(\mathrm{C}-2)$, respectively, showing that peaks were immune complexes. The new peak was purified by HPLC as a single peak; it dissociated into two peaks (HSA and antibody) when treated with $8 \mathrm{M}$ guanidine hydrochloride. When the immune complex was derived from IgG, the molar

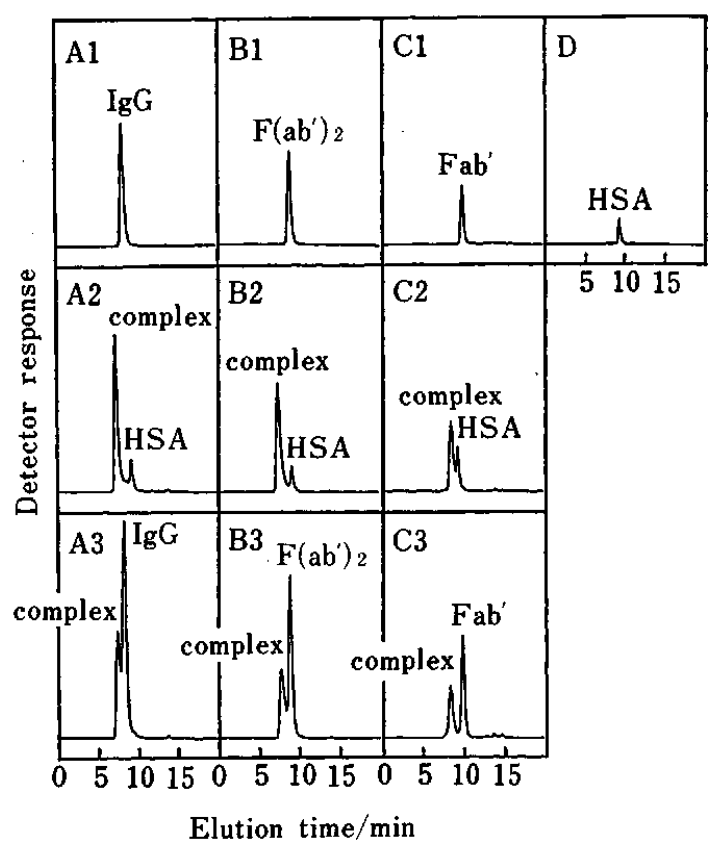

Fig. 1 Chromatographic pattern of the reaction product. The reaction and HPLC analysis were carried out as described under "Experimental". Analysis of the reaction mixture of (A), IgG: A-1, $1 \mu \mathrm{M}$ IgG; A-2, $1 \mu \mathrm{M}$ IgG and $3 \mu \mathrm{M}$ HSA; and A-3, $2.5 \mu \mathrm{M}$ IgG and $1 \mu \mathrm{M}$ HSA. (B), F(ab') ${ }_{2}$ : B$1,1 \mu \mathrm{M} \mathrm{F}\left(\mathrm{ab}^{\prime}\right)_{2} ; \mathrm{B}-2,1 \mu \mathrm{M} \mathrm{F}\left(\mathrm{ab}^{\prime}\right)_{2}$ and $3 \mu \mathrm{M}$ HSA; and B-3, $2.5 \mu \mathrm{M} \mathrm{F}\left(\mathrm{ab}^{\prime}\right)_{2}$ and $1 \mu \mathrm{M}$ HSA. (C), Fab': C-1, $1 \mu \mathrm{M}$ Fab'; $\mathrm{C}-2,1 \mu \mathrm{M}$ Fab' and $3 \mu \mathrm{M}$ HSA; and C-3, $2.5 \mu \mathrm{M}$ Fab' and $1 \mu \mathrm{M}$ HSA. (D), $1 \mu \mathrm{M}$ HSA without antibodies. ratio of HSA and IgG of the isolated peak was calculated to be 1.8. However, when the complex was derived from $F\left(a b^{\prime}\right)_{2}$ of Fab', the peaks of $F\left(a b^{\prime}\right)_{2}$, Fab' and HSA were incompletely separated during elution. Although the molar ratios of the composition of the peaks obtained from $F\left(a b^{\prime}\right)_{2}$ and Fab' could not be calculated, the retention times of the dissociated peaks were the same as those of $F\left(a^{\prime}\right)_{2}, F a b$, and HSA. The antibodies and HSA used were proved to be immunologically pure, since they reacted completely in the presence of a large excess of HSA or antibodies, respectively (Fig. 1, A-2, B-2, and C-2).

\section{Effect of sample dilution}

In HPLC columns, since samples are diluted with the eluent, we could investigate the effects of dilution of the immune complex. A mixture of $2 \mu \mathrm{M}$ IgG and $4 \mu \mathrm{M}$ HSA ( $70 \mu \mathrm{l}$ each) was diluted with buffer A 10 to 1000 times. It was possible to measure as little as $\mathbf{5 0} \mathrm{fmol}$ per single injection of proteins at $220 \mathrm{~nm}$, when the signal/ noise $(S / N)$ ratio (the peak height of a sample divided by that of the base-line noise) was about three. The retention times and patterns of the chromatograms were not changed by dilution. The relationship between the peak height of the immune complex on each chromatogram and their dilutioin factor was linear (data not shown). The same results were obtained with a mixture of $4 \mu \mathrm{M}$ antibody and $2 \mu \mathrm{M}$ HSA ( $70 \mu \mathrm{l}$ each). These results indicated that the immune complex did not dissociate within $1 \mathrm{~h}$, even at a low concentration of $2 \mathrm{nM}$. The immune complex was diluted in the column less than 30 times, since the injection volume was $100 \mu 1$ and the elution volume was about $3 \mathrm{ml}$. We therefore used a higher concentration than the required minimum of $60 \mathrm{nM}$ in order to eliminate the effects of dilution in all of the experiments.

\section{Effects of the reaction time}

The course of the formation of immune complexes was studied with the three monoclonal antibodies and their fragments. We used $20 \mu \mathrm{l}$ of each antibody at a concentration of $15 \mu \mathrm{M}$ and $80 \mu \mathrm{l}$ of $12.5 \mu \mathrm{M}$ HSA in buffer $\mathrm{A}$ and were allowed to react at $25^{\circ} \mathrm{C}$. After $30 \mathrm{~s}$, 2,20 , and $120 \mathrm{~min}, 70 \mu \mathrm{l}$ of the reaction mixture was sampled and analyzed by HPLC. The chromatogram and the peak heights did not change as the reaction time increased. The monoclonal antibodies and their fragments all reacted completely with HSA within $30 \mathrm{~s}$ under these conditions.

\section{Binding sites of antibodies}

The reactivity of the two antigen binding sites of the IgG molecule was examined. One micromole of monoclonal antibody HA3, or its fragments, was reacted with various concentrations of HSA (from $100 \mathrm{nM}$ to $6 \mu \mathrm{M}$ ). The amount of immune complex formed when of IgG, $F\left(a b^{\prime}\right)_{2}$ or Fab' was used was proportional to the amount of HSA added when the concentration of HSA was below about 2, 2, and $1 \mu \mathrm{M}$, respectively (Fig. 2). We 


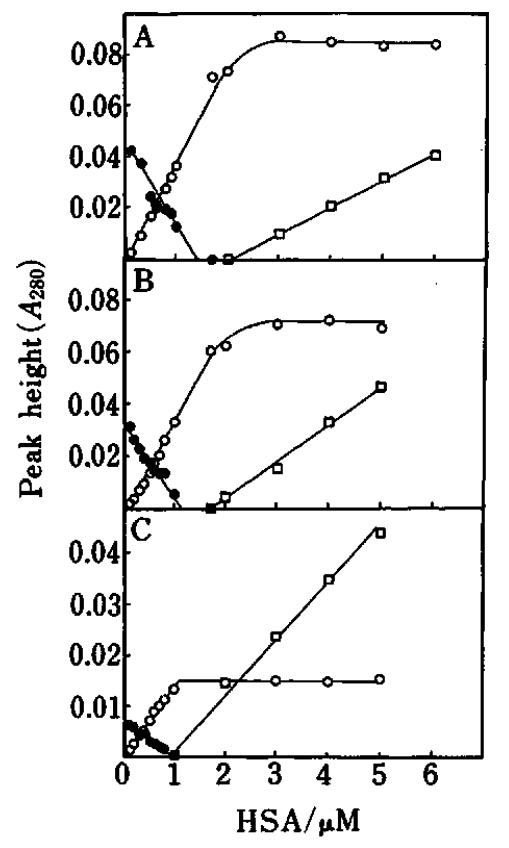

Fig. 2 Titration of the binding sites of an antibody by HSA. The peak heights of the immune complexes and the free forms on the chromatogram were plotted against the concentration of HSA added. The amounts of the immune complex $(O)$, the free form of the antibody $(\Theta)$, and the free form of HSA ( $\square$ ) were measured. A, IgG; B, F( $\left(\mathrm{bb}^{\prime}\right)_{2} ; \mathrm{C}, \mathrm{Fab}$.

extrapolated from the straight parts of the curves shown in Fig. 2 in order to estimate: 1) the concentration of HSA when there is no antibody in free form, and 2) the concentration of HSA when the free form of HSA first begins to appear. The values that were obtained for Fab' were theoretical; the disappearance of the free form of Fab' and the appearance of the free form of HSA were at both $1.0 \mu \mathrm{M}$. Therefore, the antigen-antibody molar ratio of the immune complex derived from Fab' was always one, and the reaction of Fab' with the antigen was stoichiometric. Further, the epitope of HSA was only one with the monoclonal antibody HA3 used. The two forms of the immune complex may have been produced when IgG or $F\left(a b^{\prime}\right)_{2}$ was used, in which case the molar ratio of HSA and the antibody was 1 or 2; we could not separate these two forms. Since the extinction coefficients of the two forms at $280 \mathrm{~nm}$ may be different from each other, the concentration of the immune complexes in the reaction mixture could not be estimated accurately. Further, since the amount of free antibody decreased linearly as HSA was added, the two forms of the immune complex would be equivalent to each other. In the case of IgG and $F\left(a b^{\prime}\right)_{2}$, the concentration at which the free antibody disappeared was smaller than that in the case where the free antigen appeared. Free IgG disappeared at an antigen concentration of $1.4 \mu \mathrm{M}$. This means that the molar ratio (HSA and IgG) of half the immune complex was 1.0, and that of the remainder was 2.0 when all of the IgG molecules were bound to HSA. These results indicate that two binding sites of IgG reacted in the same way with the antigen. The

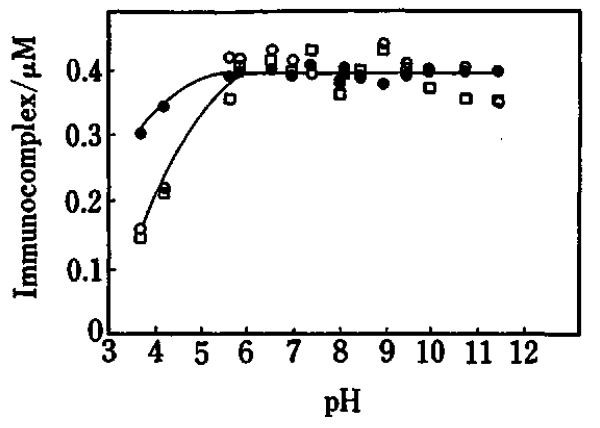

Fig. 3 Effects of pH on the reaction with IgG, $\mathrm{F}\left(\mathrm{ab}^{3}\right)_{2}$, and Fab'. The amounts of the immune complex with IgG $(\Theta)$, $\mathrm{F}\left(\mathrm{ab}^{\prime}\right)_{2}(\mathrm{O})$, and Fab' $(\square)$ were measured. The reaction mixture of $10 \mu \mathrm{M}$ antibody and $0.4 \mu \mathrm{M}$ HSA was analyzed. Buffers used: $0.1 \mathrm{M}$ acetate, for $\mathrm{pH} 3.6-4.2 ; 0.1 \mathrm{M}$ phosphate, for $\mathrm{pH} 5.5-7.5 ; 0.1 \mathrm{M}$ Tris-HCl, for $\mathrm{pH} 7.2-9.3$; and $0.1 \mathrm{M}$ glycine, for $\mathrm{pH} 8.0-11.5$.

binding activity of the second binding site of IgG was not altered when the first binding site was occupied by HSA. At HSA concentrations from 1.4 to $2.0 \mu \mathrm{M}$, all of the binding sites were saturated with HSA. In the case of $F\left(a b^{\prime}\right)_{2}$, the disappearance point of free $F\left(a b^{\prime}\right)_{2}$ was $1.1 \mu \mathrm{M}$ and the point at which HSA began to appear was $1.7 \mu \mathrm{M}$ (Fig. 2). These values are smaller than those of IgG. Since Fab', derived from the $F\left(a b^{\prime}\right)_{2}$, bound to HSA perfectly (as described above), the binding sites of $F\left(a b^{\prime}\right)_{2}$ were not destroyed by pepsin digestion of IgG. When the first site of $F\left(a b^{\prime}\right)_{2}$ is occupied by HSA, the reactivity of the second site may be altered. The Fc region of IgG may act so as to maintain the threedimensional structure that makes possible an antigenantibody interaction at the two binding sites.

\section{Effects of $p H$}

The optimum $\mathrm{pH}$ of the immunoreaction was between $\mathrm{pH} 6.0$ to 8.5 when IgG and its fragments derived from HA3 were used (Fig. 3). The amount of the immune complex with $F(a b)_{2}$ or Fab' was less than the amount with IgG at acidic pHs (2.0 to 5.0). At alkaline $\mathrm{pHs}$, the amount of immune complex was less with the Fab' fragment, but not with IgG or the $F(a b)_{2}$ fragment. The amount of immune complex did not increase, even when the reaction time was prolonged for up to $60 \mathrm{~min}$. The reaction came to completion within $20 \mathrm{~min}$, even at these extreme pHs. The decreased amount of immune complexes at acidic $\mathrm{pH}$ are due to an increased amount of unreacted antibodies. The reactivity of the IgG molecule may be greater than that of its fragments at these extreme $\mathrm{pHs}$, due to the contribution of the $\mathrm{Fc}$ fragment.

\section{Epitope typing of monoclonal antibodies}

Epitope typing of monoclonal antibodies can be easily carried out on HPLC. After the first monoclonal antibody was allowed to react with HSA, another clone was added, and the formation of a new immune complex was searched for. Twenty microliters of a $5 \mu \mathrm{M}$ IgG solution was mixed with $80 \mu \mathrm{l}$ of $1.25 \mu \mathrm{M}$ HSA; then, 


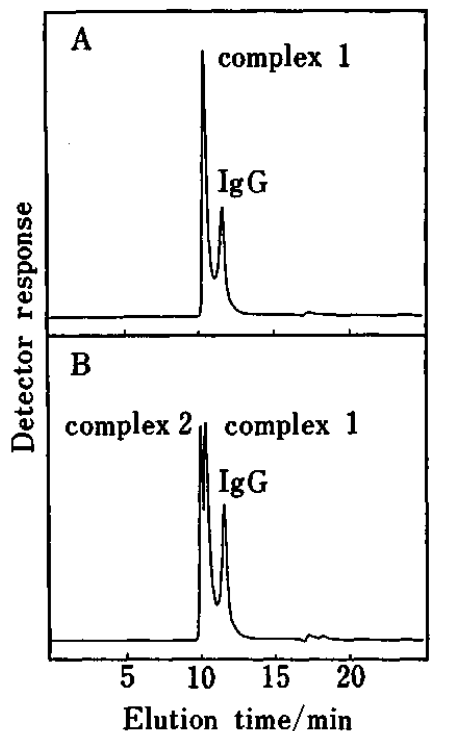

Fig. 4 Chromatograms of the reaction mixture when two monoclonal antibodies were used. The flow rate was $0.8 \mathrm{ml} / \mathrm{min}$. A, monoclonal antibody HA4 $(0.3 \mu \mathrm{M})$ was added to the mixture of $1 \mu \mathrm{M}$ HA3 and $1 \mu \mathrm{M}$ HSA; B, monoclonal antibody HA2 $(0.3 \mu \mathrm{M})$ was added to the mixture of $1 \mu \mathrm{M} \mathrm{HA} 3$ and $1 \mu \mathrm{M}$ HSA.

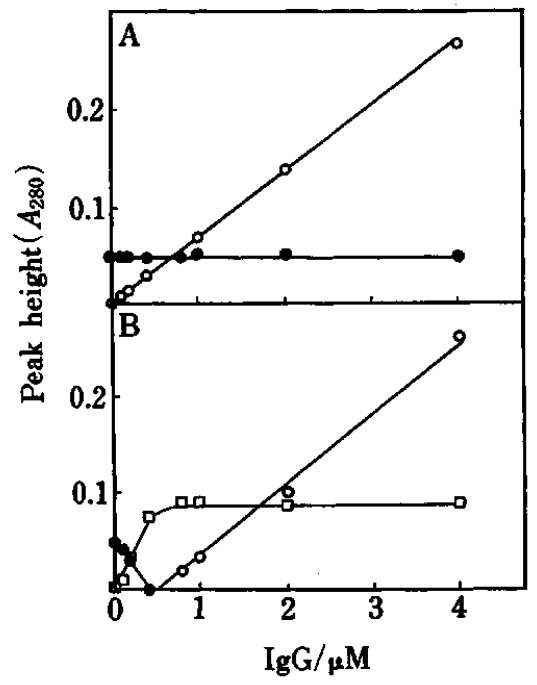

Fig. 5 Epitope typing of monoclonal antibodies. The amounts of immune complex $1(\Theta)$, immune complex $2(\square)$, and the free form of the second $\operatorname{IgG}(O)$ were measured on a Diol-200 column. A, combination of HA3 and HA4; B, combination of HA2 and HA3.

$20 \mu \mathrm{l}$ of a different IgG solution from a different clone at a concentration of 0.6 to $24 \mu \mathrm{M}$ was added at room temperature. After $30 \mathrm{~min}, 70 \mu \mathrm{l}$ of the reaction mixture was analyzed by HPLC. Only one immune complex was found when antibodies HA3 and HA4 were used (Fig. 4A). The concentration of the immune complex did not change, and the added free antibody increased in a dose-dependent way (Fig. 5A). However, in a combination with antibodies HA2 and HA3 this second immune complex, which had a higher molecular weight than that of the first, was eluted in front of it (Fig. 4B). In this case, the amount of the first immune complex decreased as that of the second, larger immune complex, increased; the free antibody was detected only after the first immune complex disappeared. When antibodies HA2 and HA4 were combined, the same results were obtained as in the case of HA2 and HA3, indicating that at least two epitopes existed in HSA for these monoclonal antibodies. Antibodies HA3 and HA4 recognized the same epitope, or nearby epitopes, and thus competed in bindings. The epitopes recognized by antibodies HA2 and HA3 or HA2 and HA4 were different, and were occupied independently by these antibodies to form a complex of higher molecular weight.

The separation and measurement of an immune complex from the free forms of the antigen and antibody on a gel filtration column, based on differences in the molecular mass, is described. HPLC provides a simple means for analyzing the antigen-antibody reaction in a homogeneous solution; non-specific binding reactions to solid phases do not occur in this method. Characterization of the reactions in terms of the reaction time, reactivity of the binding sites, and the effects of $\mathrm{pH}$, is easily achieved.

Epitope typing of monoclonal antibodies is particularly easy in this method. Such an immunoassay might be used not only for protein antigens, but also for hapten antigens if different columns are used (e.g., ionexchange or hydrophobic columns).

\section{References}

1. S. A. Berson and R. S. Yalow, J. Clin. Invest., 38, 996 (1959).

2. E. Engvakk and P. Perlmann, Immunochemistry, 8, 871 (1971).

3. E. Soini and I. Hemmila, Clin. Chem., 25, 353 (1979).

4. S. D. Lidofsky, T. Imasaka and R. N. Zare, Anal. Chem., 51, 1602 (1979).

5. N. Rugani, C. Dezan, B. Bellon and L. Sarda, Biochem. Biophys. Res. Commun., 177, 726 (1991).

6. G. Köhler and C. Milstein, Nature [London], 256, 495 (1975).

7. P. Parham, J. Immunol., 131, 2895 (1983).

8. O. H. Lowry, N. J. Rosebrough, A. L. Farr and R. J. Randall, J. Biol. Chem., 193, 265 (1951).

(Received December 6, 1991) (Accepted January 28, 1992) 